07

\title{
Влияние условий формирования геттера в высокоомном кремнии на характеристики PIN-фотодиодов
}

\author{
(C) И.Б. Чистохин, К.Б. Фрицлер \\ Институт ффизики полупроводников им. А.В. Ржанова СО РАН, \\ Новосибирск, Россия \\ E-mail: ichist1@yandex.ru
}

Поступило в Редакцию 6 июля 2020 г.

В окончательной редакции 20 июля 2020 г.

Принято к публикации 23 июля 2020 г.

Изучено влияние условий геттерирования в высокоомном кремнии при изготовлении PIN-фотодиодов на обратные темновые токи. Показано, что геттерирование путем использования комбинации ионного легирования фосфором и нанесения поликремниевой пленки с последующим легированием фосфором при температурах менее $900^{\circ} \mathrm{C}$ обратной стороны подложки приводит к пониженным значениям обратного темнового тока и увеличению времени жизни неравновесных носителей.

Ключевые слова: геттерирование, PIN-фотодиод, высокоомный кремний, темновые токи.

DOI: 10.21883/PJTF.2020.21.50188.18455

PIN-фотодиоды на основе высокоомного кремния $(>3 \mathrm{k} \Omega \cdot \mathrm{cm})$, выращенного методом бестигельной зонной плавки (БЗП), используются для широкого ряда приложений, в том числе для детектирования ионизирующих излучений. В частности, такие детекторы, стыкованные со сцинтиллятором, применяются в системах распознавания изображения объектов при облучении гаммаквантами или рентгеновским излучением для контроля безопасности, в промышленной томографии, медицине и научных исследованиях [1,2]. Одной из основных проблем при изготовлении PIN-фотодиода является минимизация величины темнового тока, задающего уровень шума и определяющего динамический диапазон входных усилителей. Нижний предел темнового тока обратносмещенного кремниевого PIN-фотодиода определяется генерационным током, который имеет обратно пропорциональную зависимость от величины времени жизни неравновесных носителей заряда $\tau$, чувствительной к присутствию в кристалле примесей, создающих глубокие энергетические уровни в запрещенной зоне кристалла [3]. Несмотря на высокое значение времени жизни в исходных подложках БЗП-кремния (до $10 \mathrm{~ms}$ ), в процессе изготовления по планарной технологии (главным образом при применении высокотемпературных обработок выше $1000^{\circ} \mathrm{C}$ ) $\tau$ может уменьшиться на дватри порядка из-за неконтролируемой фоновой диффузии в кремниевую подложку атомов переходных металлов $(\mathrm{Fe}, \mathrm{Cu}$ идр.) из кварцевой трубы [4]. Кроме того, из-за низкого содержания кислорода в БЗП-кремнии (менее $10^{16} \mathrm{~cm}^{-3}$ ) при высокотемпературных обработках возможно образование дислокаций, что также уменьшает $\tau$ [5]. В результате необходимо минимизировать высокотемпературные операции.

Для достижения минимальных темновых токов вследствие увеличения времени жизни $\tau$ в активной об- ласти PIN-фотодиода в работе [6] было предложено геттерирование обратной стороны кремниевой пластины в процессе изготовления путем осаждения поликристаллического кремния с одновременным легированием фосфором обратной стороны пластины при относительно низкой температуре $650^{\circ} \mathrm{C}$. В результате обратные темновые токи фотодиода были на три порядка меньше, чем в отсутствие геттерирования. Полученный эффект объяснялся наличием механических напряжений и высокой концентрацией активного фосфора в слое поликристаллического кремния, взаимодействующего с диффундирующими из подложки примесями.

Следует заметить, что при таком способе геттерирования, обеспечивающем процесс осаждения поликремния с одновременным легированием фосфором при пониженных температурах, применяется нестандартное специальное оборудование, использующее добавление в парогазовую смесь фосфина. Такие установки дорогостоящие и требуют повышенных мер безопасности. Стандартным и наиболее распространенным для диффузии фосфора является использование оксихлорида фосфора из жидкого источника [7]. Однако диффузионное легирование фосфором поликремния в этом случае происходит после его осаждения. При этом для достижения высокой концентрации фосфора в поликремнии необходимо применять повышенные температуры, что ослабляет эффект геттерирования. Известно, что эффективность геттерирования возрастает с ростом концентрации фосфора и падает с увеличением температуры [8]. В работах $[9,10]$ вместо осаждения поликремния, легированного фосфором, было опробовано ионное легирование фосфором обратной стороны подложки кремния дозой $5 \cdot 10^{15}$ [9] или $10^{16} \mathrm{~cm}^{-2}$ [10] с последующим отжигом при температуре $975^{\circ} \mathrm{C}$ в течение $150 \mathrm{~min}$. Однако полученный 


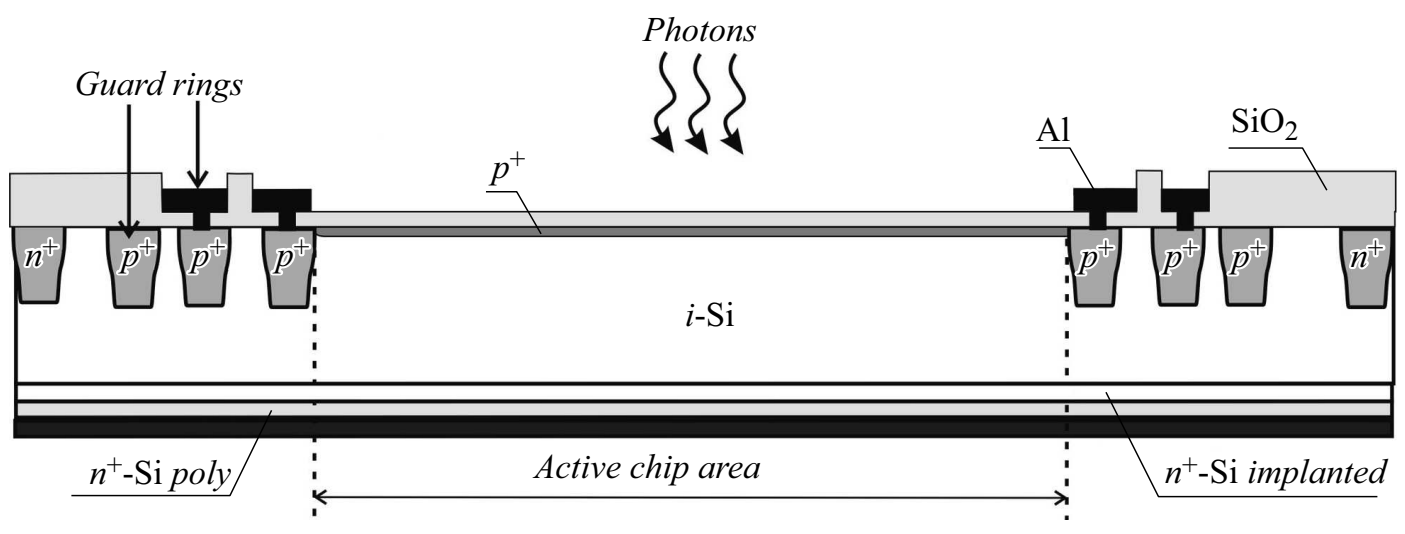

Рис. 1. Поперечный разрез PIN-диода.

уровень темновых токов фотодиодов был на два порядка выше, чем в работе [6].

Целью настоящей работы является модификация процесса геттерирования при изготовлении PIN-фотодиода на основе БЗП-кремния с использованием дополнительного ионного легирования фосфором и стандартного технологического процесса при температурах не более $900^{\circ} \mathrm{C}$.

На рис. 1 представлено поперечное сечение исследуемого PIN-фотодиода размером $5 \times 5 \mathrm{~mm}$. Диод состоит из подложки высокочистого кремния $n$-типа ориентации $\langle 100\rangle$ толщиной $360 \mu \mathrm{m}$ с удельным сопротивлением $3-5 \mathrm{k} \Omega \cdot \mathrm{cm}$ (область $i-\mathrm{Si}$ ), локальных областей $n^{+}$и $p^{+}$, создаваемых диффузионной загонкой фосфора и ионным легированием бором соответственно, пассивирующих диэлектрических слоев $\mathrm{SiO}_{2}$ и алюминиевой металлизации. Для достижения минимальных значений темновых токов обратносмещенного фотодиода имеются контакт к охранному кольцу и область геттерирования на обратной стороне подложки. Из-за высокого значения коэффициента поглощения сцинтилляционных фотонов (более $10^{4} \mathrm{~cm}^{-1}$ ) с длиной волны $480 \mathrm{~nm}$ и необходимости получения максимальных значений квантовой эффективности была выбрана толщина в активной области детектора (active chip area) $p^{+}$около $100 \mathrm{~nm}$.

Технологическая схема формирования геттерирующего слоя реализовалась в двух вариантах и включала следующие этапы.

1. На поверхность подложки кремния осуществлялось пиролитическое осаждение $\mathrm{SiO}_{2}$ посредством окисления моносилана кислородом при температуре $450^{\circ} \mathrm{C}$.

2. Удалялся $\mathrm{SiO}_{2}$ с тыльной стороны подложки.

3. Далее в первом варианте на тыльную сторону осаждался поликремний толщиной $150 \mathrm{~nm}$ с последующей стандартной диффузионной загонкой фосфора из жидкого источника при $875^{\circ} \mathrm{C}$, во втором варианте перед осаждением поликремния проводилась ионная имплантация фосфора в тыльную сторону подложки (энергия $80 \mathrm{keV}$, доза $5 \cdot 10^{16} \mathrm{~cm}^{-2}$ ), затем проводились те же технологические операции, что и в первом варианте.

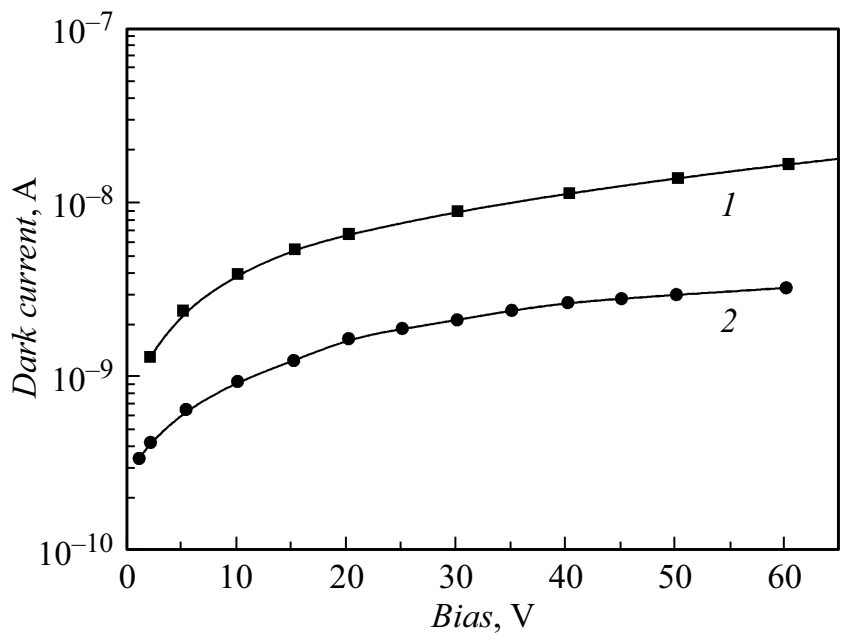

Рис. 2. Темновые обратные вольт-амперные характеристики PIN-фотодиодов, изготовленных в двух вариантах геттерирования обратной стороны подложки: $1-$ осаждение поликремния и последующая диффузия фосфора, 2 - ионная имплантация фосфора с последующим осаждением поликремния и диффузией фосфора.

После формирования геттерирующего слоя выполнялись стандартные технологические операции по изготовлению PIN-фотодиода в соответствии с конструкцией при температуре, не превышающей $900^{\circ} \mathrm{C}$.

На изготовленных в двух вариантах PIN-фотодиодах были измерены темновые обратные вольт-амперные характеристики (рис. 2). Из представленных данных видно, что уровень темновых токов диодов, изготовленных с применением второго варианта с дополнительной ионной имплантацией, примерно на порядок меньше, чем в первом варианте, и составляет $6 \cdot 10^{-9} \mathrm{~A} / \mathrm{cm}^{2}$. При этом в случае использования высокотемпературных операций (более $1000^{\circ} \mid \mathrm{C}$ ) технологического маршрута изготовления PIN-диода в обоих вариантах происходит повышение обратных темновых токов более чем на порядок. 
Для понимания механизма понижения темновых токов и качественной оценки эффективности геттерирования на изготовленных PIN-фотодиодах были также измерены времена жизни $\tau$ неравновесных носителей заряда. Измерения проводились бесконтактным СВЧ-методом [11]. Генерация неравновесных носителей заряда осуществлялась при воздействии на образцы импульсного лазерного излучения с длиной волны $1.06 \mu \mathrm{m}$. Измерения $\tau$ проводились по спаду фотопроводимости при детектировании изменения отраженного СВЧ-излучения. Величины $\tau$ составили 300 и $1500 \mu$ s для первого и второго варианта геттерирования соответственно.

Полученные данные и анализ литературы свидетельствуют о том, что уровень темновых токов фотодиодов обусловлен наличием генерационно-рекомбинационных центров, а закономерности процесса геттерирования описываются механизмом сегрегации, включающим образование ионных пар металлическая примесь (железо)-фосфор в $n^{+}$-слое $[8,9,12]$. В процессе геттерирования происходит высвобождение металлической примеси, ее диффузия к геттерной области с последующим захватом примеси и образованием комплекса с фосфором.

Кроме того, наличие легированного фосфором поликристаллического слоя и возникновение в результате его нанесения упругих деформаций обеспечивают движущую силу для диффузии, а межзеренные границы служат эффективным стоком для примесей, что еще больше усиливает эффект геттерирования [6].

Критически важным фактором в применяемом нами подходе является достижение максимального уровня легирования фосфором, а также минимизация температурного бюджета. В ходе всего технологического процесса изготовления фотодиода температура при тепловых обработках, проводимых после создания геттерного слоя, не превышала $900^{\circ} \mathrm{C}$.

Таким образом, предложен модифицированный способ формирования геттера в высокоомных (БЗП) кремниевых пластинах, позволяющий использовать стандартное технологическое оборудование и дающий возможность реализовать PIN-диоды с пониженными обратными темновыми токами.

\section{Конфликт интересов}

Авторы заявляют, что у них нет конфликта интересов.

\section{Список литературы}

[1] Moser H.-G. // Progr. Particle Nucl. Phys. 2009. V. 63. P. 186237. DOI: $10.1016 /$ j.ppnp.2008.12.002

[2] Lee S.C., Jeon H.B., Kang K.H., Kim B.B., Park H. // Nucl. Instrum. Meth. Phys. Res. A. 2018. V. 912. P. 350-353. DOI: $10.1016 /$ j.nima.2017.12.043

[3] Sze S.M. Physics of semiconductor devices. 2nd ed. Wiley, 1981. P. 21.
[4] Istratov A.A., Hieslmair H., Weber E.R. // Appl. Phys. A. 2000. V. 70. P. 489-534.

[5] Han D.J., Batignani G., Guerra A.Del. // Appl. Phys. Lett. 2003. V. 83. P. $1450-1452$. DOI: $10.1063 / 1.1602166$

[6] Holland S. // Nucl. Instrum. Meth. Phys. Res. A. 1989. V. 275. P. 537-541. DOI: 10.1016/0168-9002(89)90741-9

[7] Курносов А.И., Юдин В.В. Технология производства полупроводниковых приборов и интегральных схем. М.: Высш. шк., 1986. 367 c.

[8] Климанов E.A. // Успехи прикладной физики. 2015. Т. 3. № 2. C. 121-125.

[9] Dalla Betta G.F., Boscardin M., Pignatel G.U., Verzellesi G., Bosisio L., Ferrario L., Zen M., Soncini G. // Nucl. Instrum. Meth. Phys. Res. A. 1998. V. 409. P. 346-350. DOI: $10.1016 / \mathrm{S} 0168-9002(97) 01296-5$

[10] Seo J., Kim J., Lim H., Park J. // J. Korean Phys. Soc. 2010. V. 57. P. 44-50. DOI: $10.3938 / \mathrm{jkps} .57 .44$

[11] Владимиров В.М., Марков В.В., Сергий М.Е., Шепов В.Н. // Приборы и техника эксперимента. 2011. №2. C. 166-167.

[12] Liu A., Yan D., Wong-Leung J., Li L., Phang S.P., Cuevas A., Macdonald D. // 2018 IEEE 7th World Conf. on photovoltaic energy conversion (WCPEC). IEEE, 2018. P. 1667-1671. DOI: $10.1109 /$ PVSC.2018.8547431 